\title{
CRÍTICA DO EMPIRISMO APLICADO À PSICOPATOLOGIA CLÍNICA: DA ESTERILIDADE DO DSM A UMA SAÍDA PELA PSICANÁLISE
}

Tereza Pinto

Psicanalista, mestre em Teoria Psicanalítica pela UFRJ, mestre em Psicopatologia pela Universidade de Poitiers, doutora em Ciências da Linguagem pela Universidade de Limoges, doutora em Psicopatologia e Psicanálise pela Universidade de Paris VII, professora de Psicologia Clínica na Universidade de Paris VII (CRPMS).
RESUMO: A tradição empirista na medicina impôs seu modelo à clínica psicopatológica, e a psiquiatria construiu assim seus métodos diagnósticos sobre o modelo da observação direta. No contexto contemporâneo, essa tradição aparece, sobretudo, com a iniciativa a-teórica do DSM. Os tratamentos seguirão o ideal científico, o que aliena definitivamente o sujeito de seu sofrimento. Discute-se aqui tal proposição, contrapondo a proposta psicanalítica como única saída ao discurso científico-positivista no âmbito da psicopatologia.

Palavras-chave: Empirismo, psicopatologia, DSM, psicanálise.

ABSTRACT: Critics to empiricism applied to clinical psychopathology: from the sterility of the DSM to an issue by psychoanalysis. The empiricist tradition of medicine imposed its model upon the clinic in psychopathology. Thus, Psychiatry constructed its diagnostic methods based on the empiricists' principles of direct observation. In the contemporary context, this tradition mainly appears with the non-theoretical initiative of the DSM. Treatments will follow this scientific ideal, which definitely alienates the subject from its suffering. This paper discusses such a proposition and opposes the psychoanalytical proposal as the only solution to the scientificpositivist discourse in psychopathology.

Keywords: Empiricism, psychopathology, DSM, psychoanalysis. 
A construção do paradigma científico atual baseia seus fundamentos históricos e epistemológicos no discurso empírico-positivista que define o objeto da ciência enquanto fato publicamente observável. Isto lhe atribuiria independência de qualquer influência subjetiva e de qualquer hipótese não fundamentada apenas sobre este mesmo fato.

Essa escolha epistemológica - que marcou para todo o sempre a história da ciência contemporânea — certamente concorreu para a liberação dos saberes dos poderes políticos diversos e das crenças. No entanto, no campo médico, a rejeição da subjetividade acabou por reduzir o objeto de estudos em pura descrição de fenômenos observáveis, sobretudo quando o apoio orgânico falta ao chamado da etiologia. Nesse caso, uma simples classificação de grupos, cuja unidade se forma a partir de critérios de repetição e de duração, satisfará os espíritos "científicos". Assim, no nascimento da psiquiatria — e da clínica médica de forma geral — o organismo vira garantia de cientificidade, pois constitui o objeto publicamente visível por excelência. Todavia, a relação entre os fenômenos psiquiátricos e o organismo sempre esteve bem longe de se caracterizar como uma evidência - a ausência de tal relação seria, ao contrário, a regra. É assim que, a partir do revés desse "pressuposto de natureza" (FOUCAULT, 1957/2001, p.150), a psicopatologia se desloca em direção à descrição de fenômenos e o agrupamento de fatos similares em categorias sindrômicas.

Na medida que tal atitude epistemológica é ainda atual, em especial por intermédio dos manuais diagnósticos de distúrbios mentais, procederemos a uma breve análise histórico-epistemológica da prática psiquiátrica, com o objetivo de compreender as razões da configuração atual da clínica em psicopatologia dando lugar a tais manuais. Estes ultrapassam amplamente os objetivos de estudos estatísticos a que se propõem, o que os coloca na prática quotidiana de tratamentos psiquiátricos e psicopatológicos diversos. Com um passo a passo diagnóstico e as proposições de cuidados primários, tais manuais abarcam muito mais do que uma escala de comparação interpopulações, e tomam perigosamente, e ao mesmo tempo, os lugares do sujeito que escuta e do sujeito que fala.

Contrariamente a essa prática, a clínica psicanalítica rompe, desde Freud, com a tradição empirista, escolhendo percorrer a difícil via da subjetividade. Tal posição constituirá o desafio dessa clínica, assim como sua bandeira, e é por isso que a psicanálise representará tanto uma ruptura epistemológica no discurso clínico como uma alternativa para a sua colocação em prática.

\section{A OBSERVAÇÃO E O EMPIRISMO MÉDICO}

A medicina, sobretudo no ramo psiquiátrico, havia feito suas escolhas epistemológicas desde o princípio. Herdeira direta de uma tradição empirista do acesso ao 
conhecimento, ela fará da observação seu estandarte. Seguindo o entusiasmo com a dita objetividade científica da sua época, a psiquiatria acaba por escolher como método de trabalho o agrupamento em categorias psicopatológicas daquilo que apenas o olhar poderia discernir como semelhante ou diferente. Obviamente, nada se fazia com o apoio do método “ilegítimo” da introspecção. Os nomes que terão grande influência, inaugurando toda uma tradição em medicina, são justamente os que praticavam o método da observação de forma intensiva. Essa tendência é verificada em vários aspectos na prática, por exemplo, de Pinel, de Esquirol e de Charcot. O fenômeno bruto, reificado, existiria de fato para a psiquiatria nascente, e a realidade seria assim considerada tangível; a observação empirista serviria, desse modo, a fazer brotar os princípios e as leis dessa realidade, a nomeá-la de forma precisa de maneira que ela exista cientificamente para, em seguida, aperfeiçoar o controle da realidade em questão.

Pode-se identificar a tradição filosófica proveniente do empirismo inglês nos critérios empregados pela psiquiatria e, de forma geral, pela medicina. Thomas Sydenham, inspiração primeira do filósofo inglês John Locke, foi o responsável pelo movimento teórico do retorno a Hipócrates que marcou a medicina do século XVIII, que defendia o retorno às coisas mesmas na observação empírica e clínica (BERCHERIE, 2004). A releitura de Sydenham do ato fundador de Hipócrates foi singular, pois radicaliza a importância do olhar "ingênuo" e que rejeita hipóteses desacompanhadas de provas materiais — hipóteses presentes, paradoxalmente, nos trabalhos do grego que sustentava a importância, entre outros, dos quatro humores na etiologia patológica. Sydenham defendia, quanto a ele, a ideia de uma possível identificação dos quadros patológicos apenas observando-os, sem nenhuma pré-concepção, tais quais eles se manifestam de maneira direta à experiência sensível num encadeamento supostamente natural (DUCHESNEAU, 1972).

Essa personagem marcante da história da medicina - que foi igualmente uma influência capital para o trabalho de Pinel, via Condillac — contribuiu, com muitos discípulos ilustres, para construir a tradição empirista em medicina. Logicamente, tal tradição trouxe consigo certo ceticismo em relação aos estudos causais no campo médico, atitude que se estendeu com rapidez aos domínios da filosofia natural e epistemológica da época.

O empirismo se opõe tradicionalmente ao racionalismo, já que ele se insurge contra o pensamento cartesiano em vários aspectos: de início, pela rejeição da razão enquanto fonte de conhecimento humano sem que este seja embasado na experiência, daí o termo empirismo. Em seguida, pela defesa da experiência sensorial como único dado de base possível do conhecimento, hipótese cujo afastamento levaria a considerar os mínimos fatos da vida como fruto de uma 
ilusão sem saída, ${ }^{1}$ o que se traduz na recusa da dúvida metódica de Descartes. Enfim, pelo anti-inatismo que nega a ideia de uma disposição inata qualquer, sobretudo a de conhecer Deus.

Thomas Hobbes, empirista de primeira hora e aluno de Bacon, escreveu o que se conhece como as terceiras objeções às meditações metafísicas de Descartes para afirmar não somente seu desacordo com a desconfiança cartesiana quanto à fiabilidade dos sentidos, mas também para sustentar, no mesmo argumento, a fiabilidade do conhecimento proveniente da experiência sensível. Compreende-se assim facilmente as razões que o fazem combater de forma tão incisiva a ideia inata de Deus, pois ela pressupõe um conhecimento verdadeiro cuja matéria-prima não provém dos sentidos. Seguindo nessa direção, a célebre frase de Locke ("o homem é uma tabula rasa”) poderia ser generalizada, nesse contexto, a uma concepção segundo a qual nada existiria antes do advento da experiência (LOCKE, 1690/1989). É importante também lembrar a alegoria, elaborada por Condillac, do homem tal como uma estátua de mármore, que se animaria a partir da primeira experiência sensível que ele localizava no olfato (CONDILLAC, 1754/1788).

O racionalismo cartesiano é assim rejeitado por causa do primado da ideia em detrimento da experiência, e não por causa de uma suposta rejeição da racionalidade. Não se esquece o fato de que Hobbes era, ele mesmo, racionalista. No entanto, uma distinção da ordem das coisas é indispensável, pois, para o empirismo racionalista, com um toque todo aristotélico, a razão se constrói sempre a partir da experiência sensível, jamais antes ou sem ela.

Para Locke, a observação não seria nada além do que "os fundamentos sobre os quais nosso conhecimento da natureza e dos costumes são construídos" (LOCKE, 1706/1975, p.51), fundamentos que chegam a um espírito livre de qualquer inatismo. Assim, o espírito humano receberia passivamente os dados dos objetos externos e sensíveis que as observações lhe ofereceriam. A atividade do espírito humano se resumiria, segundo Locke, à capacidade de formar classes devido à associação de ideias simples.

Os limites do conhecimento empírico deveriam corresponder, segundo ele, aos limites do conhecimento de forma geral, como uma determinação natural que agiria sobre o homem: o saber deveria - e aqui se trata de uma profissão de fé - seguir a medida das capacidades sensíveis do homem; as elucubrações seriam somente fantasias que escondem o verdadeiro mundo observável, já que o método dedutivo era, para ele, “atividade de desocupados” (MARION, 1878, p.94).

\footnotetext{
${ }^{1}$ Este passo em direção ao ceticismo Locke não dará. Ao contrário, ele afirma que "as coisas têm qualidades reais porque elas existem realmente nas coisas” (LOCKE, 1690/1989).
} 
Reconhecem-se facilmente aqui as condições de possibilidade de uma medicina empirista para a qual não existiria outro objeto além daquele que é dado pela observação. Nesse contexto, não é nada espantoso que esse mesmo método force a psiquiatria a não considerar a fala dos pacientes, já que esta seria considerada como interpretação dos fatos e não mais os fatos mesmos: a fala não poderia assim existir como instrumento de diagnóstico, de cura ou de pesquisa.

No início do século XIX, o método da observação pura vai, no entanto, favorecer a criação de um campo propriamente psiquiátrico e, a partir daí, a organização interna deste campo com classificações, síndromes definidas e doenças determinadas. Uma vez que o empirismo faz existir o fenômeno, a psiquiatria pôde dar o passo do rompimento com a tradição médica que pregava a lesão orgânica como origem de toda patologia. Assim, mesmo sem o recurso à localização de lesões, classes sintomáticas foram construídas e uma nosografia foi esboçada. No entanto, se a observação empírica foi útil na constituição de um campo do saber, a rejeição sistemática da dedução e o uso também sistemático da observação fizeram com que a psiquiatria começasse a acumular um número infindo de casos inclassificáveis.

É importante lembrar aqui a crítica de Cassirer ao anti-inatismo lockiano fundador da observação pura, que, mesmo sendo para a psiquiatria um ato teórico de emancipação do conhecimento, não deixa de constituir uma armadilha feita de superestimação da experiência e de crença na natureza das coisas. Contrariamente a esse pressuposto, Cassirer observa que essa atitude ameaçaria: “a autonomia do espírito que não deve mais do que interpretar o papel de um simples espelho, e de um espelho que pode tão-somente refletir as imagens sem nunca poder produzi-las ou elaborá-las por sua conta própria” (CASSIRER, 1966, p.81).

Ora, como Georges Lantéri-Laura explica, a clínica médica clássica gostaria de ser uma prática de observação de um fenômeno puro, ou seja, teria como meta a construção da realidade médica a partir de uma tabula rasa, sem interferências de uma doutrina qualquer (LANTÉRI-LAURA, 1986). Porém, uma orientação assim definida é rigorosamente impraticável, pois existe sempre, na base de uma pesquisa e qualquer que seja ela, uma escolha epistemológica. Olhar tudo, sem um quadro epistemológico definido a priori faz pender o campo semântico do tudo ao nada, já que não existe objeto de pesquisa sem uma teoria que o defina enquanto tal. Mesmo que esta seja a ambição das mais inculcadas em certas correntes médicas, trata-se aqui de um impedimento de ordem lógica.

Este aspecto paradoxal já foi demonstrado pela história da medicina em geral e da psiquiatria em particular, pois, independentemente do ideal empirista, as teorias foram-se construindo. Alguns pesquisadores, como Michel Gauchet, Gladys Swain ou ainda o próprio Georges Lantéri-Laura, já haviam atentado para essa atitude quase mítica, sobretudo no que toca à psiquiatria (GAUCHET 
\& SWAIN, 1980; SWAIN, 1994). Ora, nem Pinel, nem Esquirol, nem todos os precursores da psiquiatria puderam realizar na clínica o ideal visando adotar "uma atitude descritiva que se aproxime, tanto quanto o objeto permitisse, daquela que seria adotada nas ciências físicas". ${ }^{2}$ Para rebater tal argumento, seria suficiente lembrar a teoria de Pinel sobre a alienação mental que o guiava nas suas observações "puras”.

Enquanto Lantéri-Laura fala de certo embotamento da visão dos médicos da época que se engajavam de corpo e alma na busca do ideal científico, Gauchet e Swain apostam numa ocultação voluntária de certos aspectos relativos à pratica clínica em prol do ideal. Como notam estes autores:

“A história da psiquiatria, nunca seria demais insistir, construiu-se sobre uma ausência - a ausência mesma, a precoce ausência dos criadores da disciplina frente à verdade implicada nos seus respectivos começos. Ela se escreveu a partir de um encobrimento primeiro cuja origem só pode ser imputada àqueles mesmos que se encontravam na origem.” (GAUCHET \& SWAIN, 1980, p.32)

Apesar deste paradoxo revelado pela história, hoje, o ideal empirista reafirma sua força, sobretudo na corrente dita a-teórica. A proposição, vinda diretamente dos EUA, pretende deter a solução diagnóstica imparcial, utilizável assim, em princípio, por qualquer orientação prática interessada nos estudos psicopatológicos.

Os manuais diagnósticos de doenças mentais vieram como consequência lógica e direta desta tendência. Eles aboliram as nosografias estabelecidas até então e reconstruíram uma nova proposição com a finalidade de auxiliar o psiquiatra — ou qualquer outro profissional da saúde — na identificação de um distúrbio mental recorrendo apenas aos fenômenos observáveis, sem apelo a uma teoria qualquer.

\section{O EMPIRISMO CONTEMPORÂNEO EM PSICOPATOLOGIA: O DSM}

A principal iniciativa deste gênero foi a criação de um manual para o reconhecimento de distúrbios mentais, o DSM (Diagnostic and statistical manual of mental disorders) organizado pela American Psychiatric Association (APA, 1996). Ele foi incorporado rapidamente ao quotidiano dos médicos clínicos, desde a sua primeira publicação em 1952, e continua sendo uma referência quase obrigatória (salvo opinião contrária) para todo psiquiatra responsável pela determinação oficial dos diagnósticos nas instituições destinadas a esse fim. Sob a etiqueta científica, vê-se

\footnotetext{
${ }^{2}$ Discurso de Pinel durante apresentação da sua escola de medicina na Academia Francesa de Ciências (GAUCHER \& SWAIN, 1980, p.33).
} 
assim nascer a época de ouro da prática baseada em provas (evidence based practice). Provas que só podem ser dadas pela observação dos "fatos".

Por uma questão de posicionamento teórico ou de deslocamento de responsabilidades, o fato é que o DSM se impôs e que o empirismo, na sua versão mais elementar, está mais do que nunca presente no campo da psicopatologia. Baseado em estudos estatísticos e em numerosas observações que ultrapassam em muito o universo limitado de um clínico isolado no seu consultório, esse manual oferece toda uma coleção de definições, indo do passo a passo diagnóstico até os cuidados primários.

Desde sua concepção, várias revisões foram editadas, nas quais figuram as proposições de remanejamento de categorias existentes, assim como as proposições da criação de novas entidades nosológicas. Sempre fundamentado em estudos estatísticos, o DSM instaura (ou confirma) uma cisão que não é negligenciável entre uma clínica da escuta e uma clínica da observação — ainda mais se comparadas no que diz respeito à finalidade destas práticas, já que um manual deste tipo não é nada além de uma ferramenta para chegar, custe o que custar, a um diagnóstico o mais próximo possível das categorias já propostas. É por esta razão que o DSM aparece sempre acompanhado de outros manuais mais operatórios, como, por exemplo, o que ensina a fazer um diagnóstico diferencial tipo DSM e o que propõe as técnicas a serem utilizadas nos cuidados primários (FIRST, FRANCES \& PINCUS, 2002; APA, 1995). Existe ainda, desde o ano 2000, um apoio a mais para o clínico não esclarecido em psiquiatria, um DSM facilitado, apelidado “Mini-DSM”, que visa, sobretudo, à simplificação da linguagem e do processo diagnóstico para médicos de outras especialidades ou paramédicos (APA, 2000).

Com o advento dos cruzamentos aleatórios de dados estatísticos, a observação se transforma, pois agora se trata de uma quantificação sistemática e controlada de comportamentos, sem a qual se tornaria impossível estabelecer um diagnóstico fiável: para os defensores de tal orientação, quanto mais objetivo for o diagnóstico, mais digno de confiança ele é.

De fato, num estudo realizado sobre o DSM, Ursulet considera que a abertura dada por esse manual aos dados quantificáveis seria sua grande força. Seria possível, assim, através das árvores lógicas dos diagnósticos diferenciais, traduzir tais organogramas em linguagem informática e criar "um programa de assistência ao diagnóstico pelo computador" (URSULET, 1983, p.5). Responder-se-ia em termos de presença ou ausência de tal ou tal sinal, e o programa "calcularia” o diagnóstico. Com a observação assistida por computadores, pode-se legitimamente questionar “onde está o sujeito doente?”. Talvez, no mesmo movimento, também descartar-se-ia o profissional, transformado em "programa” e cálculo informático. 
Logicamente, como a observação só pode classificar o que lhe é acessível, o DSM se deparará com o fato de ter multiplicado as categorias patológicas, já que não era possível que outro critério além da observação viesse organizar o campo. Assim, classificaram-se mais de uma centena de distúrbios psicóticos, cabendo ao clínico a escolha daquele que seria o mais "adequado" para seu paciente. Isso não afasta, no entanto, a constatação de que alguns sintomas podem continuar fora de qualquer classificação pré-estabelecida. O essencial para um diagnóstico tipo DSM seria o de encontrar, no quadro apresentado pelo paciente, pelo menos um número $\mathrm{x}$ de sintomas repertoriados e observados durante pelo menos um número $x$ de meses. Se por, um acaso, esses critérios não conseguem estabelecer uma decisão precisa quanto à categoria do distúrbio ou da síndrome, então o clínico deve recorrer à noção de distúrbio misto ou distúrbio não especificado. ${ }^{3}$ Nota-se ainda que, desde a sua terceira edição, o DSM permite a noção de comorbidade, quer dizer, a concomitância de síndromes e distúrbios num mesmo indivíduo (por exemplo, que alguém seja considerado portador de distúrbios psicóticos e de síndrome do pânico ao mesmo tempo).

Essa orientação, que leva o método da observação ao seu extremo, merece uma análise, pois é um reflexo direto de uma concepção particular do ser vivo e do humano, reduzido ao seu "ser natural", uma pura máquina. Pode-se encontrar com facilidade aqui uma definição de homem enquanto extensão, máquina biológica, tão cara ao empirismo. Assim, "a doença do doente", como dizia Canguilhem, é dissolvida por uma máquina que funciona apesar de toda e qualquer subjetividade (CANGHILHEM, 1943/2003). É por isso mesmo que ele se opôs tão fervorosamente a essa medicina moderna que já se desenhava na sua época, medicina para a qual médico e doente seriam de bom grado trocados por experts técnicos que trabalham sobre dados representados por números.

No seu trabalho de pesquisa, Marie-José Del Volgo chama a atenção para os perigos da asseptização da relação médico/paciente causada pelo excesso de zelo tecnicista. Médica fisiologista em um hospital francês, sensível à proposta psicanalítica, Del Volgo crê na clínica fundada no que ela mesma chama o "instante de dizer”, que teria chegado à medicina pelo intermédio da psicanálise. Baseada na sua longa experiência, Del Volgo constata:

"A clínica, desprezada até pouco tempo, merece reencontrar um lugar de primeira ordem em psicanálise como em medicina e a chance de um retorno da clínica em

\footnotetext{
${ }^{3}$ No manual dedicado aos cuidados primários, a recomendação é explícita: "Se sintomas psicóticos significativos são presentes, mas se os critérios diagnósticos de nenhum dos distúrbios descritos anteriormente não são preenchidos, considerar: distúrbio psicótico não especificado" (APA, 1995, p.146).
} 
medicina se encontra na psicanálise. [...] É essencialmente uma questão de restabelecer as prerrogativas da clínica, uma clínica renovada pelo método psicanalítico, uma clínica do caso a caso.” (2003, p.26-27)

Não se poderia deixar de citar o papel da indústria farmacêutica no desenvolvimento de uma ferramenta tal como o DSM. Obrigada a realizar um estudo detalhado por cada nova substância elaborada, com dados sobre sua incidência sobre uma classe determinada de distúrbios, esta indústria tinha uma grande necessidade de um padrão psicopatológico para testar os medicamentos sobre a população alvo. Além disso, os seguros-saúde exigiam a criação de uma nomenclatura padronizada, como o DSM, para poder controlar de forma mais eficaz a grade de tratamentos reembolsados e para qual tipo de doença (KIRK \& KUTCHINS,1998). Em face de tantos imperativos visivelmente externos a uma problemática científica pura, como assegurar a fiabilidade dos diagnósticos e não se interrogar sobre a pseudoneutralidade afirmada pelo DSM?

\section{OS TRATAMENTOS BASEADOS NOS MÉTODOS EMPIRISTAS: A PRÁTICA BASEADA EM PROVAS (EVIDENCE BASED PRACTICE)}

Frente a uma prática fundada na classificação de síndromes e distúrbios — determinados pela pura fenomenologia — , a cura se torna um caso praticamente impossível, e o tratamento se transforma em prescrição de paliativos. Em consequência, crescerá a importância de certos tratamentos medicamentosos, paliativos por excelência no âmbito da psicopatologia, cuja função central será sempre de diminuir o sofrimento imediato sem que as causas deste sejam colocadas em questão. É o que o psiquiatra André Gellis chama de "tratamentos sem resposta” (GELLIS, 2000, p.110).

Tais tratamentos — concentrados na prescrição de psicotrópicos — têm como característica comum o fato de calarem o sujeito na clínica. Mal-estar atenuado, o paciente muito frequentemente se acomoda e continua a consumir suas pílulas quotidianas. Claro, tal possibilidade representa um conforto de fato para o paciente que, sob efeitos destes medicamentos, dormirá à noite ou acordará pela manhã sem a experiência muito invasiva de suas mazelas. No entanto, seguindo tal orientação, as causas do sofrimento psíquico e moral continuam indiscerníveis, e é por isso que alguns destes tratamentos paliativos acabam se tornando intermináveis, retroalimentando o círculo perverso da dependência.

Nessas condições, como saber o que acontece com a evolução da queixa, da história de vida do sujeito, dos seus sentimentos ou, ao menos, de sua estrutura subjetiva? Não se saberá, pois, segundo a lógica do diagnóstico das síndromes, os tratamentos agem sobre fenômenos visíveis e compartimentados (como 
distúrbios de percepção, negativismo, sensações de ansiedade), por meio de substâncias químicas que o profissional utilizará no intuito de, ao menos, diminuir a intensidade destes fenômenos. No que tange à fala e à dimensão subjetiva destes mesmos distúrbios, um clínico assim formado não saberá tratá-las, pois simplesmente não será qualificado para fazê-lo — ou pior, não acreditará que sair do âmbito de sua prática traga vantagem alguma para o paciente. Ora, atrás da maioria das prescrições de psicotrópicos estão médicos de clínica geral, consultados por causa de uma insônia ou de uma crise de pânico. Estes profissionais, guiados por manuais como o DSM, creem habitualmente na lógica da correspondência termo a termo entre um distúrbio e uma droga, o que nos remete ao problema da disseminação quase irresponsável dos psicotrópicos na sociedade contemporânea (DUPONT, 2001). Mas, infelizmente, existe para ambas as partes um conforto estéril em adotar prescrições: por um lado, o de seguir as recomendações do médico, e por outro lado, o de agir de acordo com um manual. Trata-se sempre de um Outro que dita suas ordens.

Com a observação empirista da psicopatologia, reduz-se o sujeito a seu sintoma e propõe-se geralmente uma maquiagem à guisa de tratamento. Isso implica uma ética e uma escolha que, imputando tudo ao concreto e observável, livra-se de problemas profundos que tocam a subjetividade e seus modos de tecer laços sociais.

A escolha da orientação relativa às psicopatologias no campo médico está longe de ser inocente, como enfatiza Elisabeth Roudinesco; ao contrário, esse caminho responde a intenções bem específicas (ROUDINESCO, 1999). De fato, a medicina empirista, inconfortável com a questão do inconsciente freudiano não observável, sempre tenta retirá-lo de suas considerações sobre quadros psicopatológicos. O mito da ciência positivista não tinha outra escolha que a de se proteger da ameaça que a psicanálise poderia representar, com seus questionamentos sobre os fundamentos mesmos da prática médica habituada às síndromes bem classificadas e às promessas de curas químicas, liberando o paciente de qualquer trabalho subjetivo. Assim, os psicotrópicos puderam constituir-se como o complemento e o símbolo de uma nova torrente que levaria com ela ao mesmo tempo uma resposta simplificada e um tratamento reconhecido pela ciência.

Nos antípodas de tal escolha epistemológica empirista está o modelo clínico da escuta de um discurso subjetivo. Proposta pela psicanálise, esta clínica defende a hipótese de que o fenômeno, a sua pluralidade, possui uma organização intrínseca e que somente pelo conhecimento dessa organização é que se pode apreender a significação de um fenômeno. Essa organização estrutural das psicopatologias se fundaria na estrutura mesma da linguagem considerada enquanto lugar por excelência do registro simbólico. O modelo teórico e prático que a psicanálise 
propõe é, desse modo, muito particular, pois diagnóstico e tratamento serão abordados pela mesma via: a fala de um sujeito.

A fala será, assim, elevada ao estatuto de meio de conhecimento, de tratamento e de intervenção, pois, se o discurso é o meio da cura, sua importância está no fato de que ele está igualmente na origem dos males dos quais tenta desvencilhar-se. Aqui, as noções de prova científica e de verdade universal perdem em importância frente à densidade da realidade subjetiva. Assim, a psicanálise representou — e ainda representa hoje — um questionamento das convicções empiristas tradicionais, pois buscará métodos capazes de considerar uma realidade não observável. Numa época em que se acusa a a-cientificidade de uma clínica da escuta, seria oportuno interrogar-se sobre as consequências de uma clínica da observação sobre o sujeito.

\section{A OBSERVAÇÃO A-SUBJETIVA E A ESCUTA DE UM SUJEITO}

Por quais razões um enfoque histórico-epistemológico seria importante para a compreensão da prática clínica atual em psicopatologia? Como ele poderia nos oferecer as senhas necessárias para enxergar a clivagem que se deu, neste campo, entre a clínica da observação e a clínica da escuta? Seria o fato de uma simples escolha técnica? Não parece, e a epistemologia constitui hoje uma ajuda preciosa que permite a compreensão de que se trata, na realidade, da rejeição radical da noção de sujeito.

De fato, toda técnica e todo método, quer estes sejam considerados científicos ou não, possuem nos seus fundamentos argumentos teóricos que os justificam. O próprio discurso empírico-científico é um exemplo, pois é constituído por uma dentre várias teorias do conhecimento e do acesso à verdade. Sua teoria de base rejeita o sujeito dos processos de produção do conhecimento, substituindo-o pela noção de organismo. Torna-se evidente o fio epistemológico que une um Sydenham a um Spitzer, ${ }^{4}$ já que, no caso do DSM — como no retorno a Hipócrates do século XVII —, não se trata de um ponto de vista a-teórico, e sim de um enfoque teórico a-subjetivo.

A exclusão da subjetividade é aplicada em dois flancos: de um lado, vê-se uma total desconsideração pelo sujeito durante toda a prática diagnóstica que lhe diz respeito, já que a condição necessária seria a perspicácia do olhar do observador e sua capacidade de distinguir as categorias sindrômicas ou sintomáticas significativas. O sujeito não teria, assim, nada a dizer sobre seu “distúrbio” — a observação seria suficiente para que o cientista expert ocupasse inteiramente a posição do saber. De outro lado, o sujeito é afastado também na fase seguinte,

\footnotetext{
${ }^{4}$ Robert Spitzer, membro da APA, é o responsável pelas edições e pelas revisões do DSM.
} 
dedicada aos tratamentos para os distúrbios identificados. O uso de psicotrópicos é, por certo, o representante por excelência desta rejeição, mas não é, infelizmente, o único.

No domínio da psicologia, em que os profissionais não podem prescrever medicamentos, os tratamentos ditos "científicos" se entregam ao mesmo tipo de tarefa, quer dizer, tentam tratar os distúrbios por uma simples eliminação de sintomas. O sujeito é, desse modo, sufocado em prol de suas produções observáveis. Não é nada surpreendente que os partidários de tal clínica em psicologia sejam, ao mesmo tempo, defensores do padrão diagnóstico proposto pelo DSM.

Seguindo esse modelo, a cura seria atingida quando o sujeito tivesse conseguido desvencilhar-se de seu sintoma e que pudesse então retomar suas atividades "normais". Por exemplo, Jacques Van Rillaer defende que um paciente estaria curado de uma aracnofobia quando, no fim de um percurso dito de sensibilização progressiva, pudesse enfim segurar uma aranha em suas mãos (VAN RILLAER, 2005). No caso de uma paciente incapaz de retomar seu trabalho de condutora de ônibus depois de uma agressão sofrida, Jean Cottraux crê que a cura ter-seia dado no momento que tal dama pudesse, de fato, retomar a direção de um ônibus e, assim, reassumir seu posto de trabalho (COTTRAUX, 2004).

Verifica-se desse modo que medicamentos e condicionamentos não são métodos tão diferentes quanto se poderia considerar num exame superficial, pois desenvolvem-se sobre o mesmo paradigma a-subjetivo que permite $o$ sucesso dos manuais diagnósticos. Ora, procedimentos padronizados possuem o seguinte ponto em comum: todos os indivíduos, quaisquer que sejam eles, podem ser susceptíveis de se adequar, de responder positivamente a técnicas de adestramento ou a químicas, conseguindo, por exemplo, controlar a angústia diante de uma aranha. Porém, algumas questões, e não as menores, continuam sem resposta: Quem era esse sujeito que se manifestava pelo seu medo? Qual era sua história e que lugar era o seu nessa mesma história? Ainda: como uma "simples" aranha ou uma agressão física podem constituir-se como argumentos paralisantes para aquele sujeito com aquela história, já que um inseto não pode ser considerado como um objeto universal desencadeador de fobias? A que esses objetos respondem? Constata-se que, segundo a lógica dos manuais, tais interrogações não têm nenhum valor, pois o objetivo é apenas, explicitamente, tornar um indivíduo operacional, apagando os sintomas, que foram detectados - claro - com a ajuda de tais manuais. Aqui, o discurso científico obriga, e empirismo e pragmatismo vão de par.

Evocando os trabalhos de Del Volgo, sugerimos acima que uma alternativa a esse modelo empirista a-subjetivo está na orientação clínica psicanalítica, porque ela se fundamenta sobre a escuta de um sujeito. Contrariamente a qualquer prática 
que o rejeite, a clínica psicanalítica, através da sua escolha epistemológica, inclui o sujeito em todos os momentos que constituem sua própria prática.

Georges Canguilhem já havia demonstrado, no seu artigo "O que é a psicologia?”, que o sentido de uma expressão patológica poderia ser contemplado seja de um ponto de vista epistemológico que busca a objetividade do sentido, seja numa perspectiva que buscaria, quanto a ela, o sentido subjetivo de uma unidade de análise sui generis como o sintoma psicopatológico (CANGUILHEM, 2002). As teorias clínicas do sentido objetivo estariam alinhadas pelo modelo médico, enquanto as do sentido subjetivo tratariam o sintoma como a expressão de uma subjetividade, e não simplesmente de um corpo mecânico. Essa distinção implica outra, decisiva para a prática clínica, e ela trata da ação do clínico sobre o sintoma. Se se parte do princípio que o sintoma possui um sentido objetivo, isso significa que sua formação e sua desconstrução se passam sem nenhuma intervenção do sujeito. Tal ponto de vista se adequa ao "pressuposto de natureza" de que falava Foucault. Contrariando este pressuposto, as clínicas que consideram o sentido subjetivo do sintoma constituem-se sobre as bases de uma noção de sujeito presente e engajada na construção e na eventual desconstrução de sua patologia. Mais radical que Canguilhem, Foucault considera que o sentido do sintoma teria sido de fato descoberto pela psicanálise, já que ele parte da ideia que toda produção de significação seria subjetiva (FOUCAULT, 1957/2001). Assim a noção de "sentido objetivo" perderia sua pertinência. ${ }^{5}$

A clínica psicanalítica seria assim totalmente inserida numa tradição teórica da subjetividade do sentido, o que explica as razões de uma prática não padronizada, uma clínica do caso a caso, do singular, sem generalização de regras universais enrijecendo uma relação qualquer entre uma causa patológica e um efeito psicossomático ou sintomático. De fato, como observa Del Volgo, nenhum outro discurso se aproxima tanto da "doença do doente", tal como definiu Canguilhem.

Graças a seu ponto de vista sobre o sentido (subjetivo) do sintoma, Freud pôde desenvolver seu método clínico construído sobre a fala do paciente. Nas suas Lições de introdução à psicanálise, Freud discute longamente este aspecto, que considera como o ponto de bifurcação entre a psicanálise e a psiquiatria de seu tempo (FREUD, 1916a/1999). Esta última não estaria à procura de uma subjetividade embotada pelos sintomas visíveis - ao contrário, já que a psiquiatria tinha sido totalmente incapaz de escutar a histérica e de ver, além dos sintomas, o sofri-

\footnotetext{
${ }^{5}$ Pode-se constatar a posição de Foucault na passagem seguinte: "Foi no interior do sistema freudiano que se produziu a grande transformação da psicologia; foi no curso da reflexão freudiana que a análise causal se transformou em gênese de significações, que a evolução deu lugar à história e que o recurso à natureza foi substituído pela exigência da análise do meio cultural" (FOUCAULT, 1957/2001, p.156).
} 
mento de um sujeito. Freud já denunciava a falta de disposição dos médicos ao tratar dos “doentes dos nervos", coisa que se refletia no pouco tempo de escuta e na desconsideração do material proveniente dela. Sem saber o que fazer desse conteúdo, das "misérias de toda uma vida”, o médico, ironiza Freud, tenderia a dar rapidamente um conselho que poderia ser resumido em: "faça um pouco de hidroterapia” (FREUD, 1916a, 1999, p.315). Mas a elucidação do caso continuaria intacta, assim como um prognóstico fiável, já que o médico, sem o apoio de uma escuta subjetiva, não saberia dizer as razões de um determinado quadro.

Freud não apenas traz o sintoma psicopatológico para o domínio subjetivo, mas ainda o considera uma formação que substitui a palavra, veiculando um conteúdo recalcado, da mesma forma que o sonho, o lapso e o chiste. A tese freudiana é simples, mas revolucionária em seu tempo: a mesma força inconsciente que desemboca sobre um sintoma neurótico estaria na origem de outros tipos de formas significativas, como os sonhos. O ponto comum entre elas seria a significação desconhecida que se apresenta como um enigma a ser resolvido. Em outros termos, a aparente lacuna significativa do sintoma se apresentaria como a insistência de uma questão sem resposta (FREUD, 1916b/1999). Ora, tal concepção não permite práticas padronizadas nem diagnósticos universais, pois a lacuna de um recalque somente pode ser considerada no caso preciso em que se apresenta. Não há possibilidade de se fazer uma clínica subjetiva em massa e, nesse ponto, todas as releituras da obra de Freud estão de acordo. A psicanálise representa, assim, a única verdadeira alternativa ao discurso empirista por ter-se desvinculado do discurso da ciência desde seus primórdios, nos seus fundamentos mais profundos.

Para essa clínica, não se trata, como querem os “cientistas”, de crer em superstições ou de se lançar numa prática adivinha, mas de restituir ao sujeito seu próprio sofrimento e sua responsabilidade, abandonando assim as práticas do saber afirmado do Outro difundidas pelos manuais psiquiátricos. Do ponto de vista do sujeito, essas clínicas são um instrumento a mais na alienação do doente de sua própria doença, o que representaria, ao contrário do que pensam os que se autoproclamam científicos, retroceder e retomar a direção do passado histórico da psicopatologia. 


\section{REFERÊNCIASS}

AMERICAN PSYCHIATRIC ASSOCIATION. (1995). DSM-IV: Primary care. Washington: APA Press. . (1996). DSM-IV-TR: Diagnostic and statistical manual of mental disorders: fourth edition, text revision. Washington: APA Press.

(2000). Quick reference to the diagnostic criteria from DSM-IV-TR. Washington: APA Press.

BERCHERIE, P. (2004) Histoire et structure du savoir psychiatrique: les fondements de la clinique 1. Paris: L'Harmattan.

CANGUilHeM, G. (1943/2003). Le Normal et le pathologique. 9 éd. Paris: PUF.

(1968/2002) “Qu'est-ce que la psychologie ?”, in Études d'histoire et de philosophie concernant les vivants et la vie. 7 éd. Paris: Vrin.

CASSIRER, E. (1966). La philosophie des lumières. Paris: Fayard.

CONDILLAC, E. (1754/1788). Traité des sensations. Paris: Barrois aîné.

COTTRAUX, J. (2004). Les visiteurs du soi. Paris: Odile Jacob.

DEL VOLGO, M. (2003). La douleur du malade: clinique, psychanalyse et médecine. Ramonville Saint-Agne: Érès.

DUCHESNEAU, F. (1972). “John Locke”, in CHÂTELET, F. (org) Histoire de la philosophie, v. IV. Paris: Hachette.

DUPONT, J-C. (2001). “Psychopharmacologie”, in HOTTOIS G. \& NISSA J-N. (org) Les Mots de la bioéthique. Bruxelles: De Boeck.

FIRST, M. \& FRANCES, A. \& PINCUS, H. (2002). DSM-IV-TR, Handbook of differential diagnosis. Washington: APA Press.

FOUCAULT, M. (1957/2001). “La psychologie de 1850 à 1950”, in Dits et écrits, vol. 1 (1954-1975). Paris: Gallimard.

FREUD, S. (1916a/1999). "Psychanalyse et psychiatrie”, in Conférences d'introduction à la psychanalyse. Série traductions nouvelles. Paris: Gallimard.

(1916b/1999). "Le Sens des symptômes” in Conférences d'introduction à la psychanalyse. Série traductions nouvelles. Paris: Gallimard.

GAUCHET, M. \& SWAIN, G. (1980). La pratique de l'esprit humain: L'institution asilaire et la révolution démocratique. Paris: Gallimard.

GELLIS, A. (2000). Diagnósticos e psicotrópicos: uma resposta pela psicanálise, Psicologia USP. n.11. São Paulo: USP, p.107-118.

KIRK S \& KUTCHINS, H. (1998). Aimez-vous le DSM ? Le triomphe de la psychiatrie américaine. Plessis-Robinson: Synthélabo.

LANTÉRI-LAURA, G. (1986). “L’Empirisme et la sémiologie psychiatrique”, in La querelle des diagnostics. Paris: Navarin.

LOCKE, J. (1690/1989). Essai philosophique concernant l'entendement humain. Paris: Vrin.

(1706/1975). De la conduite de l'entendement. Paris: Vrin.

MARION, H. (1878). John Locke, sa vie et son œuvre. Bristol: Thoemes Ed.

ROUDINESCO, E. (1999). Pourquoi la psychanalyse? Paris: Fayard.

SWAIN, G. (1994). Dialogue avec l'insensé. Paris: Gallimard. 
URSULET, G. (1983). “Le DSM III: classification américaine des maladies mentales. Analyse historique et conceptuelle”. Tese de medicina, Université de Paris VI Pitié-Salpêtrière.

VAN RILLAER, J. (2005). "Les Thérapies cognitivo-comportementales: la psychologie scientifique à service de l'humain”, in MEYER, C. (Org). Le livre noir de la psychanalyse. Paris: Arènes.

Tereza Pinto

terezapinto@noos.fr 